Journal of Animal and Veterinary Advances 10 (14): 1867-1874, 2011

ISSN: $1680-5593$

(C) Medwell Journals, 2011

\title{
The Prevalence of Mycoplasma gallisepticum Infection in Chickens from Peninsular Malaysia
}

\author{
${ }^{1}$ Zahraa Faisal, ${ }^{1}$ Aini Ideris, ${ }^{1}$ Mohd Hair-Bejo ${ }^{2}$ Abdul Rahman Omar and ${ }^{3}$ Tan ChingGiap \\ ${ }^{1}$ Department of Veterinary Pathology and Microbiology, Faculty of Veterinary Medicine, \\ Universiti Putra Malaysia, 43400 UPM Serdang, Selangor, Malaysia \\ ${ }^{2}$ Institute of Bioscience, Universiti Putra Malaysia, 43400 UPM Serdang, Selangor, Malaysia
}

\begin{abstract}
The detection of Mycoplasma gallisepticum $(\mathrm{MG})$ infection in chickens in selected commercial farms (breeder, broiler and layer), Progeny-pipped Embryos (PE) and day old chicks Poor Quality Chicks (PQC) and Normal Chicks (NC) obtained from Peninsular, Malaysia was determined. These farms have the history of vaccination with mild live and killed $M G$ vaccine or antimicrobial prophylactic or treatment. To conduct this study, a total of 3056 samples were collected and conventional PCR test was performed using specific gene target sequence, encoding the surface protein for detection of MG directly from the clinical samples without prior isolation of the target MG. The primer was designed to bind to the adherence protein a (GAPA) and amplify a 505 bp DNA fragment and there are no secondary copies of this gene. Results revealed that five hundred seventy one positive samples of MG out of 3056 samples were obtained and the overall prevalence was $18.68 \%$. This study shows high detection of $M G$ infection through vertical and horizontal transmission from many geographically distinct areas of the country although, these farms had vaccination and treatment history. So, these results demonstrated that MG eradication program is not successful, despite the use of live and killed MG vaccines, an extensive medication program and strict biosecurity. It is recommended that PCR assay is used to monitor broiler breeder flocks for MG challenge during the laying cycle using progenies and confirm that point of lay broiler-breeder pullets are free of field $\mathrm{MG}$ strain. In addition to the importance of flock health monitoring in progenies, especially those pipped embryos and poor quality chicks and especially breeders in order to provide MG-free progeny.
\end{abstract}

Key words: Prevalence, Mycoplasma gallise pticum, chickens, progenies, PCR, gap, gene, Malaysia

\section{INTRODUCTION}

Mycoplasma gallisepticum has resulted in important problems of flock health in chicken and turkey industry worldwide (Kleven and Levisohn, 1996; Ferguson et al., 2004; Buim et al., 2009). The infection causes direct and indirect losses in breeder and layer production. The losses occurred as a result of decreased hatchability and egg production, reduced quality of day old chicks, increased mortality of chicks, reduced growth rate, increased costs of eradication procedures which involved site cleaning and depopulation, costly monitoring programs which involved serology and PCR and increased costs of control procedures which involved medication and vaccination (Ley, 2003; Raviv et al., 2008). Although, flock health programs are practiced such as usage of antibiotics and vaccination, the incidence of $M G$ infection is still prevalent in Malaysia and worldwide (Ling, 2005). According to Tan (2004), the prevalence of
MG infection in chicken flocks was high and ranging from $42-73 \%$, although isolation of $\mathrm{MG}$ ranges from $10-70 \%$. The prevalence of $\mathrm{MG}$ in commercial and village chickens in Penang, Malaysia was $85 \%$ based on Enzyme-Linked Immunosorbent Assay (ELISA) (Tan, 2004). The overall prevalence of $\mathrm{MG}$ in pipped embryos from Penang, Perak, Selangor, Melaka and Johor was $1.14 \%$ (Ling, 2005). The prevalence of $M G$ in pipped embryos from vaccinated and non-vaccinated parent stocks was 2.05 in Malaysia (Ling, 2005).

The Polymerase Chain Reaction method (PCR) proved as a valuable tool under practical diagnostic conditions and might provide the same or higher sensitivity than the isolation and the serological methods (Kempf et al., 1993; Ewing et al., 1996; Salisch et al., 1998; Mekkes and Feberwee, 2005). Accordingly, the nucleic acid detection methods are preferred as attractive alternative methods (Kempf, 1997; Feberwee et al., 2005). The use of molecular diagnostic methods on pooled swab samples from birds

Corresponding Author: Zahraa Faisal, Department of Veterinary Pathology and Microbiology, Faculty of Veterinary Medicine, Universiti Putra Malaysia, 43400 UPM Serdang, Selangor, Malaysia 


\section{J. Anim. Vet. Adv., 10 (14): 1867-1874, 2011}

flock was a costly but useful and dependable way of MG strain identification. It is useful when trying to differentiate Mycoplasmas field strain from vaccine strain. The cost of the PCR test could be reduced by pooling samples (Tyrrell and Andersen, 1994; East, 2008). PCR test was used to examine the flocks of broiler breeder for $\mathrm{MG}$ challenge through, the laying cycle and confirmation that broiler breeder pullets are free of $M G$ field strain. The propriety detection PCR primer was specifically designed to identify the gapA gene, the functional characterization of this gene highlights its significant role as an important conservation cytadhesion gene. There is still lack of information and reports in Malaysia about MG infection in different sources of eggs from breeder farms vaccinated with live, killed vaccines or treated with antibiotics. Therefore, the objectives of this study were to determine:

- The common pathogenic MG in different farms in Malaysia using PCR amplification methods

- The prevalence of MG infection in selected commercial chickens which include breeder, broiler and layer farms and selected progenies which include pipped embryos, day old poor quality and normal chicks obtained from Peninsular, Malaysia

\section{MATERIALS AND METHODS}

Samples collected from 2005-2006 from commercial chicken farms and progeny from breeder farms consisted of Pipped Embryo (PE), day old Poor Quality Chicks (PQC) and Normal Chicks (NC) from Peninsular Malaysia and farms with different CRD control measures) were obtained from Dr. Tan Ching Giap (Biologics Lab, UPM). A total of 3056 swab samples were collected and immediately stored in PPLO broth after culture in agar and kept in $-4^{\circ} \mathrm{C}$. Choanal cleft, tracheal and air sac swabs were obtained from each chicken, chick and embryo were pooled into one sample. The total numbers of 1831 samples from progenies Pipped Embryo (PE), day old Poor Quality Chicks (PQC) and day old Normal Chicks (NC). Samples were obtained from different geographically distinct areas of Peninsular Malaysia. Progenies were collected from breeder farms where the age of breeder was from 25 (peak of production) to 45 weeks and these farms have vaccination or no vaccination history.

The samples size of Pipped Embryo (PE) was 1243 samples, day old Poor Quality Chicks (PQC) was 248 samples and day old Normal Chicks (NC) was 340 samples. The total numbers of 1225 samples were obtained from commercial breeder, broiler and layer farms from different geographically distinct areas of Peninsular Malaysia and these chickens have vaccinations or no vaccination history. The swabs were removed under sterile condition and the broth was preceded for DNA extraction. Genomic DNA was extracted using a conventional salt based method with some modifications (OIE, 2004).

The 1st step of total nucleic acid extraction was lysis of cell and tissue sample. A volume of $70 \mu \mathrm{L} 10 \%$ SDS as a tissue cell lysis solution was added into each tube followed by adding a volume of $1 \mu \mathrm{L}$ of $50 \mu \mathrm{g} \mu \mathrm{L}^{-1}$ proteinase $\mathrm{K}$ into each tube. The mixtures of mycoplasma broth, SDS solution and proteinase $\mathrm{K}$ were vortexed to resuspend the cell pellet in all the tubes samples. The mixtures were incubated at $65^{\circ} \mathrm{C}$ for $30 \mathrm{~min}$ and shaken thoroughly every $5 \mathrm{~min}$.

The lysed samples were then placed on ice for $5 \mathrm{~min}$ or in the refrigerator at $4^{\circ} \mathrm{C}$ for $30 \mathrm{~min}$. Precipitation of protein and peptide was achieved by adding $300 \mu \mathrm{L}$ ammonium acetate to each of the lysed sample and vortex mixed vigorously for $10 \mathrm{sec}$. The debris was pelleted by centrifugation for $10 \mathrm{~min}$ at $14,000 \mathrm{rpm}$. A volume of $850 \mu \mathrm{L}$ of the supernatant was transferred to a clean microcentrifuge eppendorf tube and the pellet was discarded. Total nucleic acid was precipitated by adding $550 \mu \mathrm{L}$ of isopropanol to the recovered supernatant and the tube was inverted 40 times. Then the total nucleic acids were pelleted by centrifugation at $14,000 \mathrm{rpm}$ at $4^{\circ} \mathrm{C}$ for $10 \mathrm{~min}$ in a microcentrifuge. The isopropanol was then carefully poured off without dislodging the nucleic acids pellet. The total nucleic acid pellet was then centrifuged twice with $1 \mathrm{~mL} 75 \%$ ethanol for $10 \mathrm{~min}$ at $14,000 \mathrm{rpm}$.

The ethanol was carefully poured off without dislodging the nucleic acid or the pellet. The nucleic acid samples were then placed in the laminar air flow chamber overnight until the ethanol had evaporated. The DNA samples were re-suspended in $50 \mu \mathrm{L}$ of double-distilled water and used for polymerase chain reaction. The conventional PCR procedure was performed according to the method described by Marois et al. (2000) with some modifications. The primer used in this study was designed to bind to the Adherenc Protein A (GAPA) and amplify a 505 bp DNA fragment. The forward primer sequences was MG gapA 5F- TCARCGTTTCTAAGATTCCTTTTG and the reverse primer $\mathrm{MG}$ gapA 6R-GCATCAAAACCAGT AAATTCTTGG. There was no secondary copy of this gene and it was considered as one of the important conservation cytadhesion gene.

The primer of this gene target sequence was used specifically to detect $M G$ and there were no gene size polymorphisms on this gene (Tan, 2008). Emphasis on development of this method was on the need for typing of MG directly from the clinical samples without prior isolation of the target MG. Optimization was carried out 
Table 1: Reagents used in conventional PCR master mixture reaction

\begin{tabular}{ll}
\hline Reagents & Quantity \\
\hline $10 \times \mathrm{PCR}$ buffer & $2.5 \mu \mathrm{L}(10 \times)$ (Vivantis $^{\circledR}$, Malay sia $)$ \\
$\mathrm{MgCl}_{2}$ & $2.5 \mu \mathrm{L}(50 \mathrm{mM}$, Vivantis \\
dNTPs & $1 \mu \mathrm{L}\left(10 \mathrm{mM}\right.$ each, Vivantis ${ }^{\circledR}$, Malaysia $)$ \\
Primer MG-14F & $0.5 \mu \mathrm{L}(20 \mathrm{pmole})$ \\
Primer MG-13R & $0.5 \mu \mathrm{L}(20 \mathrm{pmole})$ \\
Taq polymerase & $0.2 \mu \mathrm{L}(15 \mathrm{mM}$, Vivantis \\
DNA template & $2 \mu \mathrm{L}(656 \mathrm{ng})$ \\
Distilled water & Add to a final volume of $25 \mu \mathrm{L}$ \\
Total volume tube & $25 \mu \mathrm{L}$ \\
\hline
\end{tabular}

by varying the PCR conditions, e.g., DNA concentration, amplification cycle number and primer annealing temperature. The amplification of fragment DNA was performed in an automatic thermal cycler (MyCycler, BioRad, USA). The reaction volume was set up in a $25 \mu \mathrm{L}$ reaction mixture as stated in Table 1 . The reaction procedure consisted of an initial denaturation step at $94^{\circ} \mathrm{C}$ for $5 \mathrm{~min}$ followed by 40 cycles of denaturation at $94^{\circ} \mathrm{C}$ for $1 \mathrm{~min}$, primer annealing at $60^{\circ} \mathrm{C}$ for $1 \mathrm{~min}$ and extension at $72^{\circ} \mathrm{C}$ for $1.5 \mathrm{~min}$ and ended with 1 cycle of final extension at $72^{\circ} \mathrm{C}$ for $10 \mathrm{~min}$. PCR amplified DNA fragments were detected in $1.5 \%$ agarose gel electrophoresis in TAE (1x) performed at $130 \mathrm{v} / 30 \mathrm{~min}$, stained with ethidium bromide $\left(10 \mathrm{mg} \mathrm{mL}^{-1}\right)$ and bands visualized on UV light, the expected positive samples showed as bands matched with band size $505 \mathrm{bp}$. The size of the amplified product was compared using a $100 \mathrm{bp}$ plus DNA ladder (Vivantis ${ }^{\circledR}$, Malaysia).

\section{RESULTS AND DISCUSSION}

The conventional PCR test in this study was performed using specific gene target sequence, encoding the surface protein for detection of MG directly from the clinical samples without prior isolation of the target $\mathrm{MG}$. The target MG primer was designed to bind to the adherence protein $\mathrm{A}$ ( gapA) gene and amplify a $505 \mathrm{bp}$ DNA. All field isolates from different sources, vaccine and reference strains showed identical bands patterns as presented on (Fig. 1). There were no secondary copies of this gene and it was considered as one of the important conservation cytadhesion gene. The primer of this gene target sequence was used specifically to detect $\mathrm{MG}$ and there were no gene size polymorphisms on this gene (Tan, 2008). The advantage of this study method is that direct detection of MG from swabs samples in the field condition can be done without prior isolation of the target MG.

The conventional PCR assay using gapA partial gene sequence in this study showed the limit of MG detection directly from swab samples therefore it counterpart the limit of MG detection in pure culture. The results agree with previous investigation that demonstrated the highest

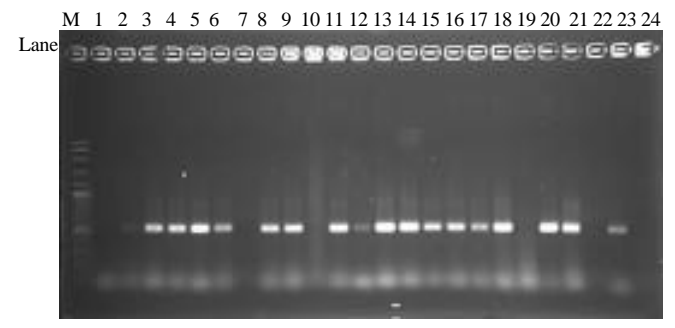

Fig. 1: PCR product of $505 \mathrm{bp}$ of positive $\mathrm{MG}$ from Pipped Eembryo (PE) samples amplified using the GAP A primer set. $\mathrm{M}=\mathrm{VC} 100$ bp plus DNA Ladder, Lanes 3-6, 8, 9, 11, 13-18, 21 positive samples tested, Lane $20=$ positive control MG S6, Lane 24 = negative control

MG detection by using the conventional PCR method and the lowest by using the commercial kit A. The comparison of the four PCR tests targeted 16S rRNA, mgc2, gapA and lipoprotein discovered that the most sensitive was gapA gene detection method (Domanska-Blicharz et al., 2008). The PCR results of pipped embryos samples showed that 160 out of 1243 samples were positive for MG obtained from 27 batches of pipped embryos and the total detection rate was $13.7 \%$ (Table 2 ). The PCR results of day old Poor Quality Chicks (PQC) showed that 42 out of 248 samples were positive for MG obtained from 13 batches of poor quality chicks and the total detection rate was $16.9 \%$ (Table 3). The PCR results of day old Normal Chicks (NC) showed that 43 out of 340 samples were positive for MG obtained from 15 batches of normal chicks and the total prevalence was $(12.6 \%)$ (Table 4$)$.

This indicated that the high presence may be due to vertical transmission, although these farms had vaccination and treatment history. All the samples were collected from the breeder group at crest age production curve that was in the late term of the eggs production curve (breeder age 52 weeks onward or $>28$ weeks egg production). Vertical transmission is very important as MG can be passed to the embryo. Vertical transmission is found lowest at periods represented by crests on the production curve and highest at periods represented by troughs on the egg production curve. The highest infection in the young chickens is due to the vertical transmission of the organisms.

The impact of the disease influences the embryo's ability in completing the process of hatching. If the infected progenies are introduced into the flock, they later might serve as a source of horizontal transmission. The failure of the yolk to incorporate the organism into the egg in some cases, the status of the maternal immunity, stress and level of infection are the reasons for the variability of 
J. Anim. Vet. Adv., 10 (14): 1867-1874, 2011

\begin{tabular}{|c|c|c|c|c|c|}
\hline No. & States & Control/treatment & Samples no. & Positive & Percent \\
\hline 1 & Melaka & Live vaccine & 105 & 28.0 & 26.6 \\
\hline 2 & Melaka & Antibiotic & 224 & 8.0 & 3.6 \\
\hline 3 & Selangor & Live vaccine & 235 & 31.0 & 13.2 \\
\hline 4 & Selangor & Antibiotic & 61 & 2.0 & 3.3 \\
\hline 5 & Negeri Sembilan & Killed vaccine & 243 & 48.0 & 19.7 \\
\hline 6 & Negeri Sembilan & Live vaccine & 55 & 0.0 & 0.0 \\
\hline 7 & Penang & Live vaccine & 101 & 22.0 & 21.8 \\
\hline 8 & Penang & Antibiotic & 47 & 11.0 & 23.4 \\
\hline 9 & Perak & Antibiotic & 96 & 20.0 & 20.8 \\
\hline 10 & Johor & Antibiotic & 76 & 0.0 & 0.0 \\
\hline Total & & & 1243 & 170.0 & 13.7 \\
\hline
\end{tabular}

Table 3: Numbers and percentages of day old poor quality chicks from various farms with positive MG by PCR

\begin{tabular}{llcrrr}
\hline No. & States & Control/treatment & Samples no. & Positive & Percent \\
\hline 1 & Selangor & Live vaccine & 145 & 15.0 & 10.3 \\
2 & Johor & Antibiotic & 18 & 1.0 & 5.6 \\
3 & Penang & Live vaccine & 6 & 4.0 & 66.7 \\
4 & Negeri Sembilan & Live vaccine & 20 & 0.0 & 0.0 \\
5 & Negeri Sembilan & Killed vaccine & 59 & 22.0 & 37.3 \\
Total & & & 248 & 42.0 & 16.9 \\
\hline
\end{tabular}

\begin{tabular}{|c|c|c|c|c|c|}
\hline No. & States & Control/Treatment & Samples no. & Positive & Percent \\
\hline 1 & Selangor & Live vaccine & 87 & 8.0 & 9.2 \\
\hline 2 & Selangor & Antibiotic & 101 & 2.0 & 2.0 \\
\hline 3 & Negeri Sembilan & Killed vaccine & 128 & 28.0 & 21.9 \\
\hline 4 & Negeri Sembilan & Live vaccine & 10 & 0.0 & 0.0 \\
\hline 5 & Penang & Live vaccine & 14 & 5.0 & 35.7 \\
\hline Total & & & 340 & 43.0 & 12.6 \\
\hline
\end{tabular}

organism shedding through vertical transmission. The detection rate of $\mathrm{MG}$ vertical transmission is lower in birds infected with $M G$ virulent strains early in life when compared to higher incidence of the MG vertical transmission when the birds are infected during lay. The rate of the vertical transmission differ from $50 \%$ in the acute phase to $<3 \%$ in the chronic phase of infection and always the entire flocks derived from the infected parents become MG positive (Levisohn and Kleven, 2000). Initially, controlled exposure to the field MG strain before the lay was considered a way to decrease the natural infection impact occurring during lay (Bencina and Dorrer, 1984).

The PCR results of commercial breeder, broiler and layer farms showed that 316 out of 1225 samples were positive for $\mathrm{MG}$ obtained from 17 batches of commercial farms and the total prevalence was (25.8\%) (Table 5). This indicated that the high presence may be due to horizontal transmission although, these farms had vaccination and treatment history. Probably the $\mathrm{MG}$ organism was transmitted through infected birds, eggs and wild birds, vehicles or fomites (Jordan, 1985). There were other probable factors that lead to the $\mathrm{MG}$ infection in the flock such as the type of management and other stressors such as cold during the rainy season and health programmes of the flock which includes vaccination could be the stressful conditions to the chickens and lead to reduced immunity against $\mathrm{MG}$ infection. Total 81 positive samples of MG out of 496 samples using PCR were obtained from pipped embryos farms and the prevalence was $16.33 \%$. These breeder farms were vaccinated with mild live vaccine. Total 48 positive samples of MG out of 243 samples using PCR were obtained from pipped embryos farms and the prevalence was $19.75 \%$. These breeder farms were vaccinated with killed vaccine. Tatal 41 positive samples of MG out of 504 samples using PCR were obtained from pipped embryos farms and the prevalence was $8.14 \%$. These breeder farms were treated with antibiotic (Table 6). About 19 positive samples of MG out of 171 samples using PCR were obtained from day old poor quality chicks farms and the prevalence was $11.11 \%$. These breeder farms were vaccinated with mild live vaccine.

Total 22 positive samples of MG out of 59 samples using PCR were obtained from day old poor quality chicks farms and the prevalence was $37.29 \%$. These breeder farms were vaccinated with killed vaccine. One positive sample of MG out of 18 samples using PCR were obtained from day old poor quality chicks farms and the prevalence was $5.60 \%$. These breeder farms were treated with antibiotic (Table 6). Total 13 positive samples of MG out of 111 samples using PCR were obtained from day old normal chicks farms and the prevalence was $11.71 \%$. These breeder farms were vaccinated with mild live 


\begin{tabular}{|c|c|c|c|c|c|c|}
\hline No. & Type/breed & States & Control/treatment & Samples no. & Positive & Percent \\
\hline 1 & Village & Penang & Antibiotic & 397.0 & 137 & 34.5 \\
\hline 2 & Village & Kedah & Antibiotic & 135.0 & 33 & 24.4 \\
\hline 3 & Breeder & Melaka & Live vaccine & 122.0 & 0 & 0.0 \\
\hline 4 & Layer & Melaka & Antibiotic & 120.0 & 62 & 51.7 \\
\hline 5 & Broiler & Selangor & Antibiotic & 190.0 & 17 & 8.9 \\
\hline 6 & Layer & Negeri Sembilan & Killed vaccine & 96.0 & 29 & 30.2 \\
\hline 7 & Broiler & Negeri Sembilan & Antibiotic & 134.0 & 11 & 8.2 \\
\hline 8 & Broiler & Perak & Antibiotic & 31.0 & 27 & 87.1 \\
\hline Total & & & & 1225.0 & 316 & 25.8 \\
\hline
\end{tabular}

Table 6: Numbers and percentages of pipped embryos, poor quality and normal chicks from various farms with positive MG by PCR

\begin{tabular}{|c|c|c|c|c|c|c|}
\hline \multirow[b]{2}{*}{ Treatment/samples } & \multicolumn{2}{|l|}{ Live vaccine } & \multicolumn{2}{|l|}{ Killed vaccine } & \multicolumn{2}{|l|}{ Antibiotics } \\
\hline & Positive/total & Detection rate & Positive /total & Detection rate & Positive/total & Detection rate \\
\hline Pipped embryos & $81 / 496$ & 16.33 & $48 / 243$ & 19.75 & $41 / 504$ & 8.14 \\
\hline Poor quality chicks & $19 / 171$ & 11.11 & $22 / 59$ & 37.29 & $1 / 18$ & 5.60 \\
\hline Normal chicks & $13 / 111$ & 11.71 & $28 / 128$ & 21.86 & $2 / 101$ & 2.00 \\
\hline
\end{tabular}

*Incidence rate within rows with different superscripts differed significantly at $\mathrm{p}<0.05$

vaccine. About 28 positive samples of MG out of 128 samples using PCR were obtained from day old normal chicks farms and the prevalence was $21.86 \%$. These breeder farms were vaccinated with killed vaccine. Two positive samples of MG out of 101 samples using PCR were obtained from day old normal chicks farms and the prevalence was $2 \%$, these breeder farms were treated with antibiotic (Table 6).

The statistical analysis was done and all datasets were expressed as percentage incidence for the farms. Comparisons were made across vaccination, types and antibiotic treatment for the incidence rates using one way analysis of variance. Significantly, different incidence rates were elucidated using the Tukey HSD test. All statistical procedure was conducted at $95 \%$ confidence level.

This study showed high detection rate of MG infection from many geographically distinct areas of the country. In progenies coming from breeder farms that have been vaccinated with mild live vaccine the total detection rate was $16.33 \%$ in pipped embryos, $11.11 \%$ in day old poor quality chicks and $11.71 \%$ in day old normal chicks. This might be due to the mild vaccine strains ts-11 and $6 / 85$ used in the present study induced milder post vaccination reactions than the $F$ strain. They did not persist in the respiratory tract during the trial period and give weaker immunological response. However, the $\mathrm{F}$ strain vaccinated chickens had the mildest air sac lesions after challenge with a virulent $\mathrm{R}$ strain (Evans and Hafez, 1992). The correlation between infectivity, immunogenicity and pathogenicity of MG strains is complicated. The protection level of live MG vaccine is associated to the virulence of the vaccine ( $\mathrm{Lin}$ and Kleven, 1982). Higher levels of circulating antibodies was induced by the more virulent $\mathrm{F}$ strain as compared to low levels of circulating antibodies that was induced by the less virulent ts-11 and 6/85 vaccine strains but the protection does not correlate with the circulating antibody titer (Lam and Lin, 1984; Talkington and Kleven, 1985; Whithear et al., 1990). In progenies coming from breeder farms that have been vaccinated with killed vaccine, the total detection rate was $19.75 \%$ in pipped embryos, $37.29 \%$ in day old poor quality chicks and $21.86 \%$ in day old normal chicks. This finding agree with previous study which reported that killed bacterin immunization is an important part of a control program but it cannot be used alone to eradicate $\mathrm{MG}$ and provide minimal protection from the disease and the economic losees (Kleven, 2008). Challenged vaccinates may be infected with pathogenic MG thus, egg transmission and lateral spread still occurs (Levisohn and Kleven, 2000).

The progenies coming from breeder farms that were treated with antibiotic, the total detection rate was $8.14 \%$ in pipped embryos, $5.60 \%$ in day old poor quality chicks and $2 \%$ in day old normal chicks. This result indicated that the medication can not be used as a method for eradication of MG. However, several medication approaches have been used successfully to limit vertical transmission, avoid the MG infection effect on performance of the birds and prevent flock infection. Several antibiotics including the macrolides, tetracyclines and flouroquinolones have in vitro and in vivo activities, although the mycoplasmas are resistant to antimicrobials like penicillin which affects cell wall synthesis. During the flock medication, it is impossible to separate the antimicrobial effect on $\mathrm{MG}$ and the secondary invaders, therefore in vivo response to medication did not essentially match the in vitro resistance (Levisohn, 1981; Wang et al., 2001; Ley, 2003). In the breeder farms, the highest MG was detected in the progenies collected from 


\section{J. Anim. Vet. Adv., 10 (14): 1867-1874, 2011}

breeders that were vaccinated with killed MG vaccine and the lower MG was detected in progenies collected from breeders that were vaccinated with live $\mathrm{MG}$ vaccine. However, the lowest MG was detected in the progenies collected from breeders that were treated with antibiotics. This might indicate that the pattern of MG detection rate through vertical transmission varies according to different control measures. These findings have the same opinion and confirmed the previous study in Malaysia that showed the pattern of caseous airsac varies according to different control measures for $\mathrm{MG}$ in the breeder farm. Also, most caseous airsac lesions were observed in embryos of eggs that were collected throughout the eggs production curve for breeders that were vaccinated with killed MG vaccine and in embryos of eggs that were collected when the egg production were at crest production curve for breeders that were vaccinated with live $M G$ vaccine (Tan, 2008).

In this study, the overall prevalence of MG from progenies and commercial chickens farms was $18.68 \%$. This rate seems high consent with the previous reports that mentioned the high detection rate of $\mathrm{MG}$ infection in poultry farms in Malaysia (Ganapathy et al., 2001; Mutalib et al., 2001). Based on serological test, the prevalence of $\mathrm{MG}$ in commercial and village chickens in Penang, Malaysia was found to be $85 \%$ (Tan, 2004). Another investigation demonstrated that the MG prevalence in pipped embryo from vaccinated and non vaccinated parent stock was $2.05 \%$, however a further report mentioned that the overall prevalence of $\mathrm{MG}$ in pipped embryos from five states in Malaysia was $1.14 \%$ (Ling, 2005). The highest detection finding in this study was also recorded previously in Malaysia by Shah-Majid (1996) who conducted a seroprevalence study on village chickens using ELISA and found that $26 \%$ samples were positive to $\mathrm{MG}$. Observations of $\mathrm{MG}$ in village chickens from other countries include Benin (Chrysostome et al., 1995), Botswana (Mushi et al., 1999), India (Chakraborty et al., 2001) and Zambia (Pandey and Hasegawa, 1998). The overall prevalence in these investigations ranged from 26 (Malaysia) to 62\% (Benin). Another study recorded, 13-32\% seroprevalence of $\mathrm{MG}$ infection in some selected poultry farms in the southern part of Bangladesh (Amin et al., 1992). The highest MG detection rate might be due to the replacement of breeding stock with the same flock progeny. However, concentrated nature of poultry production give the opportunity for recycling of the pathogens due to population production density and generating the huge multi age sites (Pradhan, 2002). The additional factors that contribute $\mathrm{MG}$ infection are poor ventilation, litters contamination, lack of movement restriction of the technical personnel, visitors and such other persons as well as other bio-security measures (Dulali, 2003). Another factor which relate to $\mathrm{MG}$ infection are tracheal epithelium damage as a result of vaccine virus replication, formalin fumigation, ammonia, dust and inflammatory response (Anderson et al., 1968; Carlile, 1984). The immune system plays important role on the epidemic $\mathrm{MG}$ infection. Previous studies on the immunodominant surfaces proteins of MG demonstrated high rate of expression variation in these proteins, switching and modulation of the immunity that suggested the variable expression in these proteins might be the essential adaptive mechanism which enables the MG organism to escape from the host, adaptation to the environments of the host resulting to the tissue invasion and producing the chronic infection (Bencina et al., 1994; Garcia et al., 1994; Glew et al., 2000; Levisohn and Kleven, 2000).

\section{CONCLUSION}

A sensitive PCR test was developed to detect MG at the level of the gapA gene. Total 561 positive samples of MG out of 3056 samples with overall prevalence $18.68 \%$ were detected in this study using PCR test which indicated that the PCR assay was very sensitive and specific technique used to monitor the breeder flocks and progenies coming from breeder farms for $\mathrm{MG}$ challenge during the laying cycle and confirm that point of lay broiler breeder pullets are free of $\mathrm{MG}$ field strain. The early detection of the disease through monitoring is essential in preventing $\mathrm{MG}$ vertical transmission.

There is high prevalence of $M G$ infection in commercial chickens and progenies originally from breeder farms. This shows that $\mathrm{MG}$ eradication program (elimination of the positive flocks) had failed despite the practice of using mild live vaccine, killed MG vaccine, an extensive medication program and strict biosecurity measures. It is recommended that vaccination program utilizing the live $\mathrm{MG}$ vaccine be implemented in the farm to prevent vertical transmission to displace the $\mathrm{MG}$ field strain from the breeder flocks and to eradicate MG from the breeder flocks.

\section{REFERENCES}

Amin, M.M., M.A.B. Siddique and M.M. Rahman, 1992. Investigation on chronic respiratory disease in chickens: Part-II. BAU Res. Progress, 6: 262-266.

Anderson, D.P., R.R. Wolfe, F.L. Cherms and W.E. Roper, 1968. Influence of dust and ammonia on the development of air sac lesions in turkeys. Am. J. Vet. Res., 29: 1049-1058. 
Bencina, D. and D. Dorrer, 1984. Demonstration of Mycoplasma gallisepticum in tracheas of healthy carrier chickens by fluorescent-antibody procedure and the significance of certain serologic tests in estimating antibody response. Avian Dis., 28: $574-578$.

Bencina, D., S.H. Kleven, M.G. Elfaki, A. Snoj, P. Dovc, D. Dorrer and I. Russ, 1994. Variable expression of epitopes on the surface of Mycoplasma gallisepticum demonstrated with monoclonal antibodies. Avian Pathol., 23: 19-36.

Buim, M.R., E. Mettifogo, J. Timenetsky, S. Kleven and A.J.P. Ferreira, 2009. Epidemiological survey on Mycoplasma gallisepticum and $M$. synoviae by multiplex PCR in commercial poultry. Pesquisa Veterinaria Brasileira, 29: 552-556.

Carlile, F.S., 1984. Ammonia in poultry houses: A literature review. World's Poult. Sci. J., 40: 99-113.

Chakraborty, D., T. Sadhukahan, D. Guha and A. Chatterjee, 2001. Seroprevalence of Mycoplasma gallisepticum in West Bengal. Indian Vet. J., 78: 855-856.

Chrysostome, C.A.A.M., J.G. Bell, F. Demey and A. Verhulst, 1995. Sero prevalences to three diseases in village chickens in Benin. Preventive Vet. Med., 22: 257-261.

Domanska-Blicharz, K., G. Tomczyk and Z. Minta, 2008. Copmparision of different molecular methods for detection of Mycoplasma gallisepticum. Bull. Vet. Institute Pulawy, 52: 529-532.

Dulali, R.S., 2003. Seroprevalence and pathology of mycoplasmosis in sonali chickens. MS Thesis, Department of Pathology, Faculty of Veterinary Science, Bangladesh Agricultural University, Mymensingh, Bangladesh.

East, I.J., 2008. Addressing the problems of using the polymerase chain reaction technique as a stand-alone test for detecting pathogens in aquatic animals. Rev. Sci. Technol., 27: 829-837.

Evans, R.D. and Y.S. Hafez, 1992. Evaluation of a Mycoplasma gallisepticum strain exhibiting reduced virulence for prevention and control of poultry mycoplasmosis. Avian Dis., 36: 197-201.

Ewing, M.L., L.H. Lauerman, S.H. Kleven and M.B. Brown, 1996. Evaluation of diagnostic procedures to detect Mycoplasma synoviae in commercial multiplierbreeder farms and commercial hatcheries in Florida. Avian Dis., 40: 798-806.

Feberwee, A., D.R. Mekkes, J.J. de Wit, E.G. Hartman and A. Pijpers, 2005. Comparison of culture, PCR and different serologic tests for detection of Mycoplasma gallisepticum and Mycoplasma synoviae infections. Avian Dis., 49: 260-268.
Ferguson, N.M., V.A. Leiting and S.H. Klevena, 2004. Safety and efficacy of the avirulent Mycoplasma gallisepticum strain $\mathrm{K} 5054$ as a live vaccine in poultry. Avian Dis., 48: 91-99.

Ganapathy, K., J.M. Bradbury, C.G. Tan, A.R. Mutalib and C.T. Tan, 2001. Seroprevalence of Mycoplasma gallisepticum in commercial broilers and layer chickens in Malaysia. Proceedings of the 2nd International Congress/13th VAM Congress and CVA-Australia/Oceania Regional Symposium, Aug. 27-30, Kuala Lumpur, pp: 108-109.

Garcia, M., M.G. Elfaki and S.H. Kleven, 1994. Analysis of the variability in expression of Mycoplasma gallisepticum surface antigens. Vet. Microbiol., 42: 147-158.

Glew, M.D., G.F. Browning, P.F. Markham andI.D. Walker, 2000. PMGA phenotypic variation in Mycoplasma gallisepticum occurs in vivo and is mediated by trinucleotide repeat length variation. Infect. Immu., 68: 6027-6033.

Jordan, F.T.W., 1985. Gordon memorial lecture: 1 People, poultry and pathogenic mycoplasmas. World's Poult. Sci. J., 41: 226-239.

Kempf, I., 1997. DNA amplification methods for diagnosis and epidemiological investigations of avian mycoplasmosis. Acta Vet. Hungaria, 45: 373-386.

Kempf, I., A. Blanchard, F. Gesbert, M. Guittet and G. Bennejean, 1993. The polymerase chain reaction for Mycoplasma gallisepticum detection. Avian Pathol., 22: 739-750.

Kleven, S.H. and S. Levisohn, 1996. Mycoplasma Infections of Poultry. In: Molecular and Diagnostic Procedures in Mycoplasmology, Tully, J.G. (Ed.). VolII, Academic Press, New York, pp: 283-292.

Kleven, S.H., 2008. Control of avian mycoplasma infections in commercial poultry. Avian Dis., 52: $367-374$.

Lam, K.M. and W. Lin, 1984. Resistance of chickens immunized against Mycoplasma gallisepticum is mediated by bursal dependent lymphoid cells. Vet. Microbiol., 9: 509-514.

Levisohn, S. and S.H. Kleven, 2000. Avian mycoplasmosis (Mycoplasma gallisepticum). Rev. Sci. Technol., 19: 425-442.

Levisohn, S., 1981. Antibiotic sensitivity patterns in field isolates of Mycoplasma gallisepticum as a guide to chemotherapy. Isr. J. Med. Sci., 17: 661-666.

Ley, D.H., 2003. Mycoplasma gallisepticum infection. In: Diseases of Poultry, Saif, Y.M., H.J. Barnes, A.M. Fadly, J.R. Glisson, L.R. McDougald and D.E. Swayne (Eds.). Iowa State Press, Ames, Iowa, pp: $722-744$. 
Lin, M.Y. and S.H. Kleven, 1982. Pathogenicity of two strains of Mycoplasma gallisepticum in turkeys. Avian Dis., 26: 360-364.

Ling, Y.M., 2005. Prevalence of Mycoplasma gallisepticum and Mycoplasma synoviae in pipped embryos. DVM Thesis, Universiti Putra Malaysia.

Marois, C., F. Oufour-Gesbert and I. Kempf, 2000. Detection of Mycoplasma synoviae in poultry environment samples by culture and polymerase chain reaction. Vet. Microbiol., 73: 311-318.

Mekkes, D.R. and A. Feberwee, 2005. Real-time polymerase chain reaction for the qualitative and quantitative detection of Mycoplasma gallisepticum. Avian Pathol., 34: 348-354.

Mushi, E.Z., M.G. Binta, R.G. Chabo, M. Mathaio and R.T. Ndebele, 1999. Detection of Mycoplasma gallisepticum and Mycoplasma synoviae antibodies in the sera of indigenous chickens by rapid serum agglutination test at Mmopane, Gaborone, Botswana. Onderstepoort. J. Vet. Res., 66: 333-334.

Mutalib, A.R., A. Yardi, N. Pargini, K. Ganapathy and Z. Zakaria, 2001. Polymerase chain reaction as an alternative method for diagnosis of Mycoplasma gallisepticum in chickens. Proceedings of the 2 nd International Congress/13th VAM Congress and CVA-Australia/Oceania Regional Symposium, Aug. 27-30, Kuala Lumpur, pp: 75-76.

OIE, 2004. Avian Mycoplasmosis. In: Manual of Diagnostic Tests and Vaccines for Terrestrial Animals, OIE (Ed.). 5th Edn., Office International des Epizootics, Paris.

Pandey, G.S. and M. Hasegawa, 1998. Serological survey of Mycoplasma gallisepticum and Mycoplasma synoviae infection in chickens in Zambia. Bull. Anim. Health Produc. Afr., 46: 113-117.

Pradhan, M.A.M., 2002. Studies on avian mycoplasmosis: Prevalence, isolation, characterization and antigenic properties. Ph.D. Thesis, Department of Microbiology and Hygiene, Faculty of Veterinary Science, Bangladesh Agricultural University, Mymensingh, Bangladesh.
Raviv, Z., S.A. Callison, N. Ferguson-Noel and S.H. Kleven, 2008. Strain differentiating real-time PCR for Mycoplasma gallisepticum live vaccine evaluation studies. Vet. Microbiol., 129: 179-187.

Salisch, H., K.H. Hinz, H.D. Graack and M. Ryll, 1998. A comparison of a commercial PCR-based test to culture methods for detection of Mycoplasma gallisepticum and Mycoplasma synoviae in concurrently infected chickens. Avian Pathol., 27: 142-147.

Shah-Majid, M., 1996. Detection of Mycoplasma gallisepticum antibodiesin the sera of village chickens by the enzyme-linked immunosorbent assay. Trop. Anim. Health Produc., 28: 181-182.

Talkington, F.D. and S.H. Kleven, 1985. Evaluation of protection against colonization of the chicken trachea following administration of Mycoplasma gallisepticum bacterin. Avian Dis., 29: 998-1003.

Tan, C.G., 2004. Prevalence of Mycoplasma gallisepticum and Mycoplasma synoviae in commercial and village chickens in Penang. DVM Thesis, Universiti Putra Malaysia.

Tan, C.G., 2008. Gene size polymorphism and pathogenicity in embryonated eggs of Mycoplasma gallisepticum isolated from commercial chickens. Master Thesis, Universiti Putra Malaysia.

Tyrrell, P. and P. Andersen, 1994. Efficacy of sample pooling for the detection of Mycoplasma gallisepticum and Mycoplasma synoviae utilizing PCR. Proc. Western Poult. Dis. Conf., 43: 62-62.

Wang, C., M. Ewing and S.Y. Aarabi, 2001. In vitro susceptibility of avian mycoplasmas to enrofloxacin, sarafloxacin, tylosin and oxytetracycline. Avian Dis., 45: 456-460.

Whithear, K.G., Soeripto, K.E. Harringan and E. Ghiocas, 1990. Safety of temperature sensitive mutant Mycoplasma gallisepticum vaccine. Aust. Vet. J., 67: $159-165$. 